\title{
Correction: OxHDL controls LOX-1 expression and plasma membrane localization through a mechanism dependent on NOX/ROS/NF-KB pathway on endothelial cells
}

Lorena Pérez · Alejandro Vallejos · Cesar Echeverria · Diego Varela · Claudio Cabello-Verrugio · Felipe Simon

Published online: 15 January 2020

(c) United States and Canadian Academy of Pathology 2020

Correction to: Laboratory Investigation

https://doi.org/10.1038/s41374-018-0151-3
Figure 2 should appear as shown below. All authors agree with the author correction.
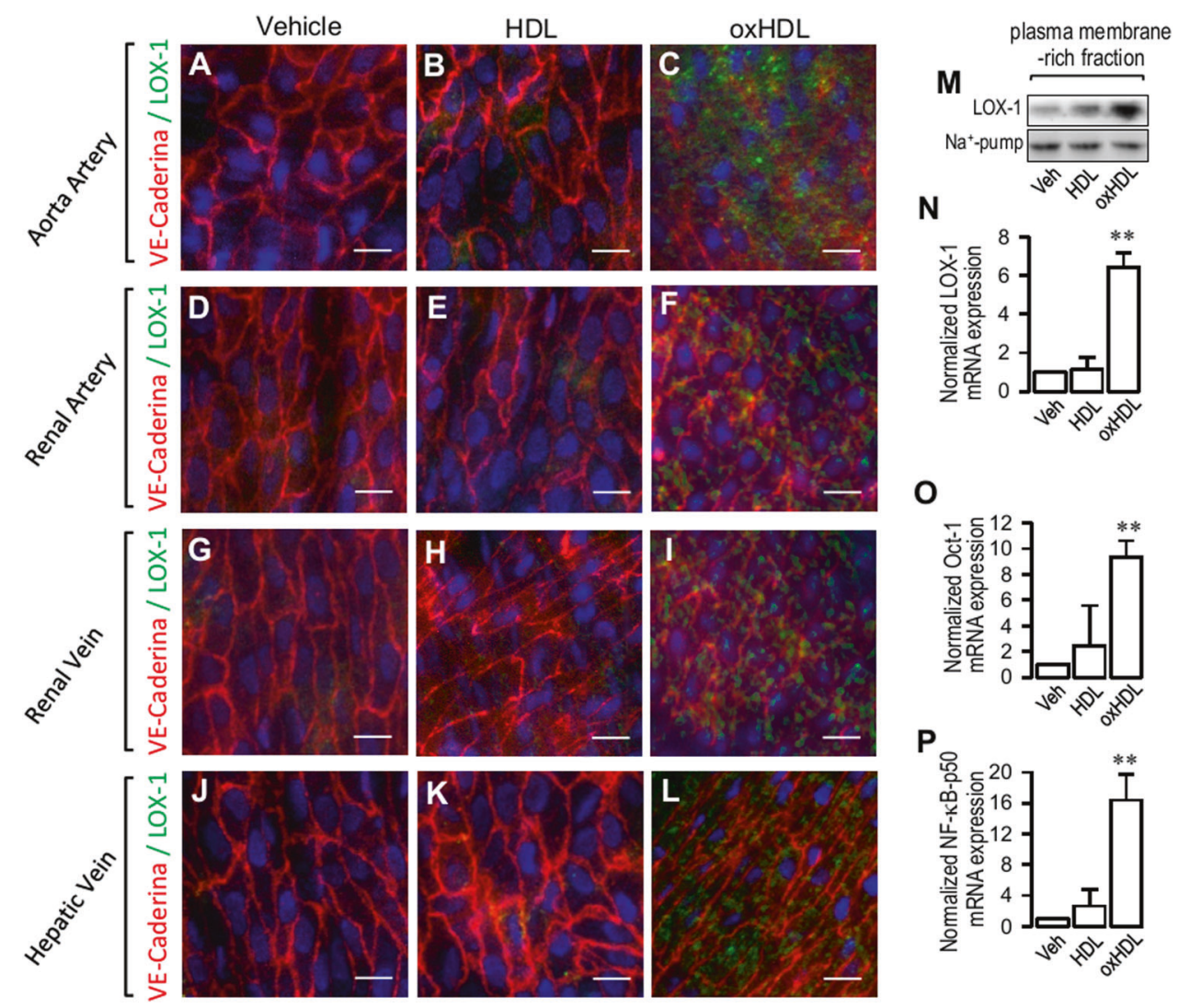

0

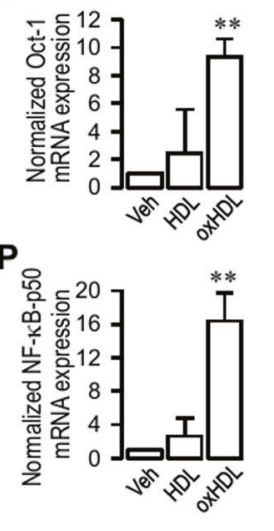

Fig. 2 